\title{
Inclusão de Surdos na Escola Municipal Marechal Castelo Branco de Jaguarão-RS
}

\author{
Deaf inclusion in the Municipal School Marechal Castelo Branco \\ Jaguarão-RS
}

\section{La Inclusión Sordos en la Escuela Municipal Marechal Castelo Branco \\ Jaguarão-RS}

\author{
Helena Beatriz Costa De Oliveira ${ }^{1}$ \\ Baiarde Cardoso ${ }^{2}$ \\ Me. Everton Fêrrêr de Oliveira ${ }^{3}$
}

\begin{abstract}
Resumo
O trabalho tem como meta mapear as ações e os materiais usados na Escola Municipal Marechal Castelo Branco na cidade de Jaguarão -RS -Brasil, que desenvolve praticas pedagógicas voltadas a alfabetização de alunos surdos inclusos na classe do sistema regular de ensino, recebendo alunos advindos de outras escolas do referido município. Os objetivos assentam-se em refletir sobre os materiais usados pelos educadores, educandos e demais profissionais envolvidos nas praticas pedagógicas. Como metodologia usamos o método qualitativo, analisamos o que está disponível na referida escola. Primamos pela necessidade de problematizarmos a atuação do autor deste trabalho durante o tempo de implantação das aulas, ressaltando as possibilidades de aprendizagem salientando as habilidades da escrita, da leitura e matemática em libras que são trabalhadas pelos educadores. Destacamos que durante suas atuações este profissional trabalha junto com um interprete em libras. Podemos concluir que a sociabilidade gerada através do processo de inclusão destes indivíduos nas classes regulares faz com que o material disponibilizado em libras e a convivência se tornam uma unidade caminhando juntas e trazendo um bom modelo a ser seguido.
\end{abstract}

Palavras-Chave: classe regular, escola, inclusão, libras, surdez.

\begin{abstract}
The work aims to map the actions and materials used at the Municipal School Marechal Castelo Branco in the city of Jaguarao-RS-Brazil, which develops educational practices focused on literacy deaf students included in the regular school system class, receiving students coming from other schools in the municipality. The objectives are based on reflecting on the materials used by educators, students and other professionals involved in the

\footnotetext{
${ }^{1}$ Universidade Federal do Pampa, Unipampa; Jaguarão, Rio Grande do Sul, Brasil. hhoxum@ gmail.com

${ }^{2}$ Universidade Federal do Pampa, Unipampa; Jaguarão, Rio Grande do Sul, Brasil. bayardcardoso@ hotmail.com

${ }^{3}$ Mestre em Educação; Universidade Federal do Pampa, Unipampa; Jaguarão, Rio Grande do Sul, Brasil. evertonoliveira@unipampa.edu.br
} 
pedagogical practices. The methodology we use the qualitative method, we analyze what is available in that school. We stand by the need to problematize the role of the author of this work during the time of implementation of lessons, highlighting the learning opportunities emphasizing writing skills, reading and math in pounds that are worked by educators. We emphasize that during his performances this professional works with an interpreter in pounds. We can conclude that sociability generated through the process of inclusion of these individuals in regular classes makes the material available in pounds and coexistence become one walking together and bringing a good model to follow.

Keywords: deafness, pounds, regular class, school, inclusión.

\section{Resumen}

El trabajo tiene como objetivo organizar las acciones y los materiales utilizados en la Escuela Municipal Marechal Castelo Branco, en la ciudad de Jaguarao-RS-Brasil, que desarrolla prácticas educativas centradas en la alfabetización de los estudiantes sordos incluidos en la clase regular sistema escolar, la recepción de los estudiantes procedentes de otros centros educativos del municipio. Los objetivos se basan en la reflexión sobre los materiales utilizados por los educadores, estudiantes y otros profesionales involucrados en las prácticas pedagógicas. La metodología que utilizamos el método cualitativo, se analiza lo que está disponible en esa escuela. Estamos por la necesidad de problematizar el papel del autor de este trabajo durante el tiempo de ejecución de lecciones, destacando las oportunidades de aprendizaje haciendo hincapié en las habilidades de escritura, lectura y matemáticas en libras que se trabajan por los educadores. Hacemos hincapié en que durante sus actuaciones este profesional trabaja con un intérprete en libras. Podemos concluir que la sociabilidad generada por el proceso de inclusión de estas personas en las clases regulares hace que el material disponible en libras y la convivencia convertido en uno de caminar juntos y traer un buen modelo a seguir.

Palabras claves: libras, la escuela, la inclusión, la clase regular, sordera.

\section{Introdução}

O trabalho tem como meta mapear as ações e os materiais usados na Escola Municipal Marechal Castelo Branco situada no Bairro Kennedy região periférica da cidade de Jaguarão -RS -Brasil, que desenvolve praticas pedagógicas voltadas a alfabetização de alunos surdos inclusos na classe do sistema regular de ensino recebendo alunos advindos de outras escolas do referido município. Os objetivos assentam-se em refletir sobre os materiais usados pelos educadores, educandos e demais profissionais envolvidos nas praticas pedagógicas.

Lembrando que possuem monitoramento específico durante as atividades escolares mesmo sem este profissional possuir formação especifica para desempenhar tal função. Os demais alunos a partir da $6^{a}$ serie são inseridos em disciplina de libras na referida escola.

O processo de adequação da referida escola se deu pela necessidade de um dos professores que trabalha no local em questão, este profissional possuí um filho com a deficiência auditiva, fazendo com que este educador adapta se o espaço para atender este tipo de demanda especifica, vindo mais tarde a inclusão dos demais alunos que estavam inseridos em outras escolas em classes regulares na referida cidade.

\section{Metodologia}


Como metodologia usamos o método qualitativo, analisamos o que está disponível na referida escola. $\mathrm{O}$ autor deste trabalho Baiarde Cardoso, desenvolve suas praticas pedagógicas na referida escola, nos traz uma amostra dos materiais disponibilizados em libras no local e os minicursos ofertados para os profissionais envolvidos nas praticas de ensino-aprendizagem pela Prefeitura da referida cidade.

\section{Resultados e discussões}

Primamos pela necessidade de problematizarmos a atuação do autor deste trabalho durante o tempo de implantação das aulas, ressaltando as possibilidades de aprendizagem salientando as habilidades da escrita, da leitura e matemática em libras que são trabalhadas pelos educadores. Destacamos que durante suas atuações este profissional trabalha junto com um interprete em libras.

No ambiente pelos professores e pelos demais profissionais que trabalham no local é usada apostila, figura 1 criada pela Associação dos surdos da cidade de Pelotas feita pelo professor de Libras Daniel Lopes Romeu que faz parte do corpo docente da Universidade Federal do Pampa ministrando disciplinas de libras, usa-se material impresso composto de sinais de libras associados com figuras que remetam a sua tradução, conforme figuras 2 e 3 . Os materiais citados são usados e disponibilizados para todos que trabalham ou estudam no referido local, possibilitando a troca de experiências, o aprender junto e o respeito pela diversidade de indivíduos que dali fazem seu espaço de convivência.

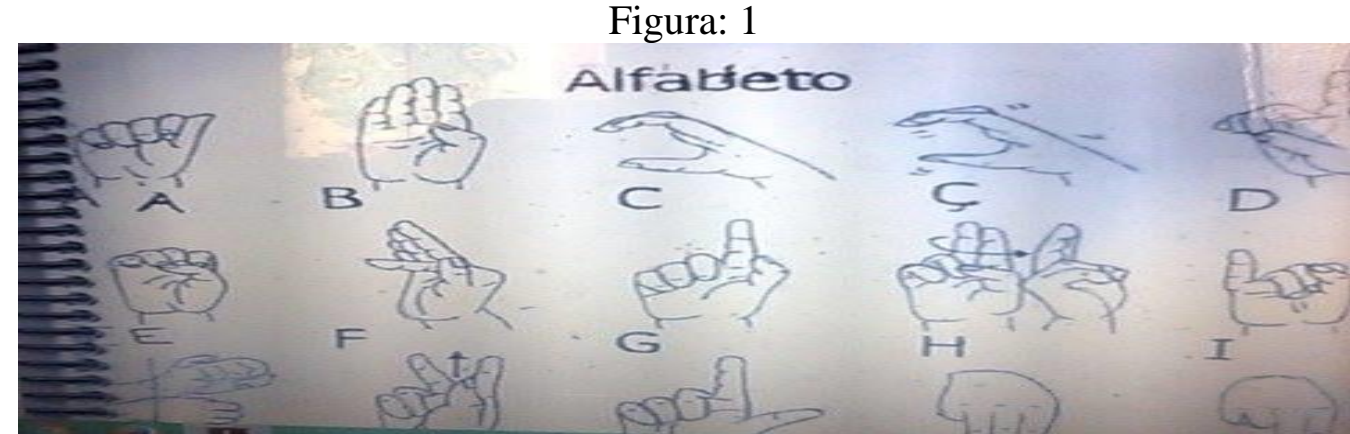

Fonte: Baiarde Cardoso

Figura: 2

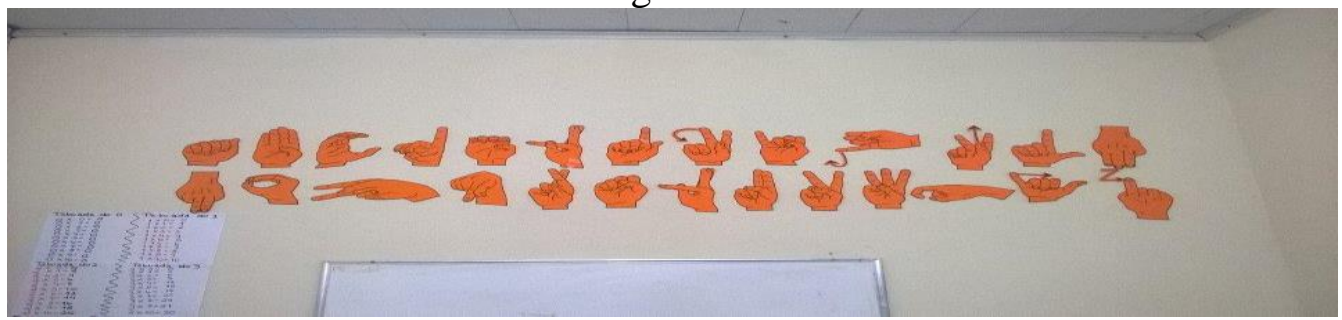


Fonte: Baiarde Cardoso

Figura:3

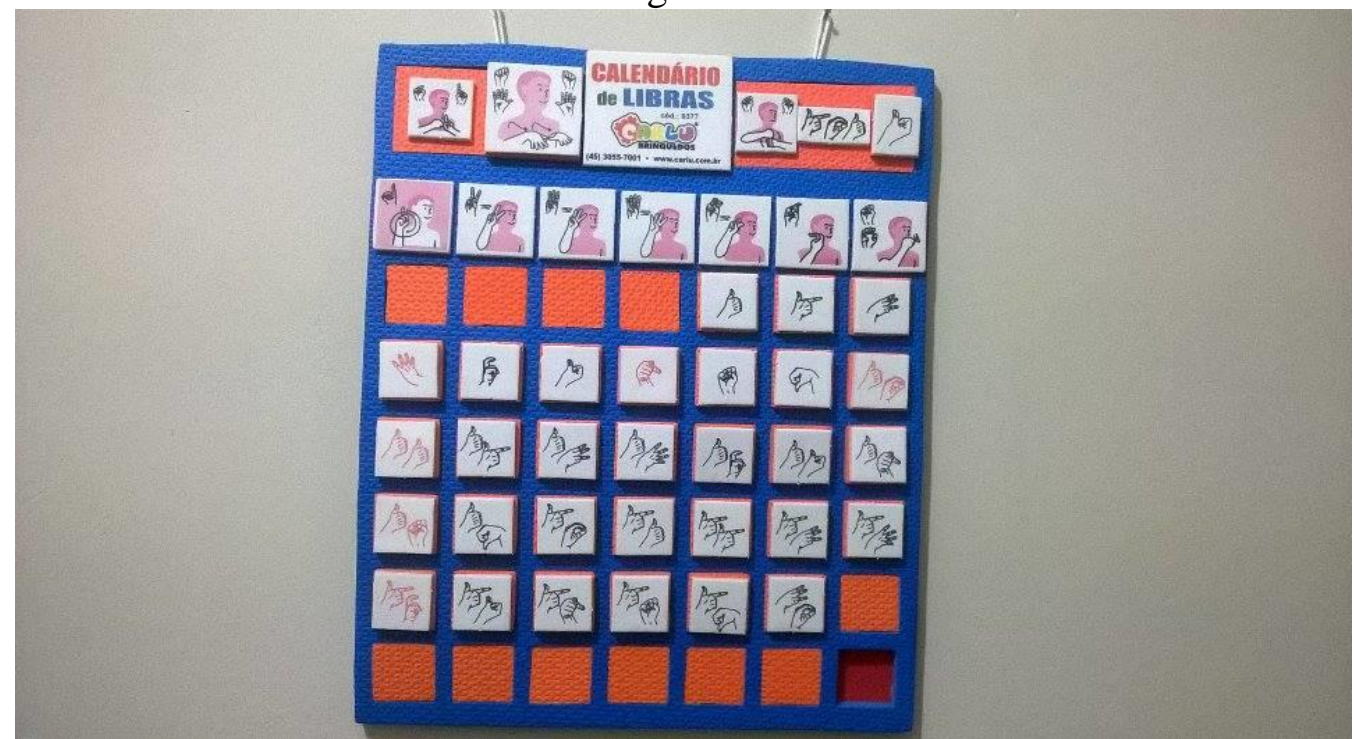

Fonte: Baiarde Cardoso

No material fotografado pelo autor do referido texto, notamos o cuidado, a perfeição com que são confeccionados os materiais, ofertando uma diversidade de sinais proporcionando um material de facil compreensão, facilitanto a comunicação entre surdos e ouvintes que dividem o mesmo espaço.

A formação é disponibilizada para aos monitores através da Prefeitura Municipal De Jaguarão que reúne uma vez ao mês estagiários monitores e professores responsáveis pelas salas de AEE (Atendimento Educacional Especializado) momento de interação e de aprendizagem onde são ofertados quatro minicursos nas modalidades: LIBRAS, Língua Portuguesa para alunos com surdez, Interpretação em LIBRAS e Instrutor de LIBRAS. Esses momentos de formação são direcionados exclusivamente para os profissionais envolvidos nas praticas na referida escola, ofertando momentos de troca de conhecimentos e de aperfeiçoamento das técnicas usados no local, possibilitando repensar as formas de inclusão e de interação dos envolvidos. 
Os demais alunos a partir da $6^{\mathrm{a}}$ serie são inseridos em disciplina de libras na referida escola, possibilitando uma maior compreensão da forma de comunicação, melhorando as trocas sociais entre os alunos surdos e os ouvintes, propiciando momentos de trocas de conhecimentos entre os envolvidos no local em questão.

Os demais alunos tendo os materiais disponibilizados em forma de cartazes, tendo a apostila disponibilizada também se empenham em aprender a linguagem em libras, facilitando o processo de inclusão que ali esta acontecendo, criando laços de amizades que podemos notar nos intervalos das aulas, se tornando um local onde a interação e a convivência se torna uma troca de conhecimentos mútuos.

A referida escola trabalha com estagiários que vem da Universidade Federal Do Pampa, Campus Jaguarão, advindos dos cursos de licenciaturas que vem desenvolverem suas praticas de estagio no local em questão, disponibiliza para estes educadores os materiais que já são usados neste local, e suas praticas de alfabetização acontecem de forma compartilhada com o monitor que acompanha os alunos que possuem a necessidade de acompanhamento.

O modelo utilizado tenta fazer com que o surdo use as palavras. Oralidade é tratada com a integração dos sujeitos surdos na comunidade de ouvintes, a professora com maior experiência da preferência aos métodos lúdicos por proporcionar às crianças surdas melhorias no desenvolvimento cognitivo e interesse, concentração por meio de jogos (tipo segue o mestre, imitação, desenhos, teatro sinalizado, brincadeiras, hora do conto com fantoches).

Do grupo de professores que atende esses alunos apenas uma professora tem conhecimentos básicos em libras. A escola oferece espaço e material especializado para facilitar a inclusão dos alunos. Eles são tranquilos, não apresentam problemas de convívio social e a família é bem atenciosa e participativa nas atividades e no acompanhamento escolar dos mesmos.

Muitos professores do ensino regular tem resistência quanto aos alunos deficientes, na maioria dos casos, a falta de conhecimento de como lidar com esses alunos, sendo assim eles se sentem despreparados para assumir esse trabalho inclusivo.

A escola acolhe o surdo em sala regular de ensino têm como finalidade promover sua participação num contexto social ampliado, para assim garantir igualdade social e educacional, permitindo um contato mais direto com a linguagem oral. Os alunos ouvintes e os surdos devem ser estimulados e motivados a se tornarem comunicativos entre si.

\section{Referencias bibliográficas}



e-ISSN 2016/Atual: 2525-7870 | e-ISSN 2015/2016: 2447-018X

Para embasar nosso trabalho trouxemos Gonçalves e Festa ( 2013, p. 3) que nos trazem um panorama das leis que regem o processo de ensino-aprendizagem dos indivíduos que possuem deficiência auditiva.

\begin{abstract}
Para a área da surdez no Brasil, existem dois documentos que norteiam as ações a respeito do sujeito Surdo. A Lei $\mathrm{n}^{\circ} 10.436 / 2002$, considerada um avanço na educação de surdos, tem sua importância ao reconhecer a LIBRAS (Língua Brasileira de Sinais) como a língua de sinais usada pela comunidade surda no Brasil. Outro documento é o Decreto 5626/2005 que regulamenta Lei $\mathrm{n}^{\circ} 10.436 / 2002$. Segundo o Decreto 5626/2005, Cap. IV, Art. 15, a educação do aluno Surdo, deve ser feito em LIBRAS e a modalidade escrita [...] como segunda língua para alunos Surdos, devem ser ministrados em uma perspectiva dialógica5, funcional e instrumental. No Art. 16 esclarece que, a Língua Portuguesa na forma oral, deve ser ofertada aos alunos Surdos, preferencialmente em turno distinto ao da escolarização, por meio de ações integradas entre as áreas da saúde e da educação, tendo a família ou o aluno o direito a opção por essa modalidade. (GONÇALVES E FESTA, 2013, p.3)
\end{abstract}

Ainda nos dias atuais Brabo ( et al, 2015, p.249) chama a atenção para os preconceitos que são usados pelos profissionais que estão inseridos no âmbito escolar e que se acham despreparados para trabalharem suas praticas pedagógicas neste complexo local de inclusão social onde alunos com deficiências são inseridos.

Penso que, diante de um universo tão variado de alunos de diferentes licenciaturas, com saberes específicos inerentes ao seu campo de conhecimento, é valido que se procure trabalhar, antes de tudo, a apropriação da historia da educação especial, o estado da politica nacional de educação especial na perspectiva da educação inclusiva e, sobre tudo, a sensibilização desse alunado quanto ao respeito a diversidade e aos princípios de cidadania para que, caso recebam, em sua docente, um aluno com deficiências possam intervir educacionalmente, para além da velha cantilena do "eu não recebi formação para atender esse aluno" ( Brabo et al, 2015, p.249).

Para Rijo (2009, p.20) nos traz suas análises sobre a inclusão de alunos surdos em diversas escolas da rede regular de ensino tidas como "inclusivas", para ele a inclusão destes alunos se faz através do intérprete que traduz em sinais tudo que o professor está expondo. $\mathrm{O}$ professor explica para os alunos ouvintes e a o intérprete traduz. Neste mesmo sentido, é feito o trabalho na escola que é alvo de nossa investigação salientamos a importância do interprete neste processo de inclusão e de inclusão.

Trazendo as três formas de abordagem dos processos educacionais das crianças surdas trazemos Rechico e Marostega ( 2002, p.7-8) mostram, primeiramente o Oralismo é um processo onde o meio de comunicação entre o surdo e o ouvinte deve ser o da oralidade possibilitando o desenvolvimento da língua oral, em um segundo processo educacional que é 

e-ISSN 2016/Atual: 2525-7870 | e-ISSN 2015/2016: 2447-018X

o da comunicação total, ondes todas as formas de comunicação são permitidas como gestos, escrita, sinais formais e de demais recursos são aceitas para desenvolver-se linguisticamente e por fim o processo de bilinguismo sendo compreendida a língua de sinais como sua primeira língua e a língua da sociedade onde esta inserido como sua segunda língua.

\begin{abstract}
A busca de um programa educacional para os surdos marca a implementação e evolução de abordagens utilizadas com esses sujeitos. Várias mudanças ocorreram, envolvendo a aceitação da língua de sinais no processo educacional das crianças surdas. A primeira abordagem corresponde ao Oralismo. Essa filosofia visa à integração da criança surda com os ouvintes, propondo o desenvolvimento da língua oral. Isso quer dizer que o único meio do surdo se comunicar com os demais é através da oralização. Dentro dessa concepção, a surdez é vista como uma deficiência que precisa ser minimizada, precisa ser medicalizada. A segunda abordagem educacional é a da Comunicação Total, onde é defendida a idéia de que o surdo pode utilizar todas as formas de comunicação (gestos, fala, sinais formais, alfabeto datilológico, leitura labial, leitura, escrita) para desenvolverse lingüisticamente. [...] Mais recentemente foi adotada uma nova proposta de educação para surdos que corresponde à terceira abordagem, a chamada Bilingüismo. Esta assume a língua de sinais como a primeira língua, sendo a aprendizagem fundamental para que depois tenha o contato com a segunda língua que é a língua do grupo majoritário. Na visão de estudiosos, busca-se, por meio dessa corrente educacional, propor o uso e o conhecimento de duas línguas pela mesma pessoa, pois se acredita na convivência harmoniosa entre os surdos e os ouvinte e almeja-se um desenvolvimento cognitivo lingüístico paralelo entre ambos.. ( RECHICO E MAROSTEGA, 2002, p.6)
\end{abstract}

Apontando-nos a sociabilidade que começa a ocorrer com a inserção do aluno que possui deficiência auditiva na escola de alunos não surdos aparece Da Silva Araújo( et al, p.15) mostrando como a comunicação e a interação se tornam importantes no processo de inserção onde todos são professores e aprendizes aprendendo a se comunicar e a compartilhar experiências dentro do mesmo ambiente escolar.

De acordo com a pesquisa realizada, vimos que na pratica docente os professores constatam que as libras exerceu e vem exercendo grande influencia no processo educacional de estudantes surdos. Além disso, a inserção desses estudantes em sala de aula regular contribui para a socialização da língua de sinais não apenas entre surdos, como também entre ouvintes. Hoje os surdos estão mais comunicativos, com isso, buscam novos conhecimentos e a compreensão dos ouvintes através das trocas de experiências, conquistando o respeito da comunidade escolar e da sociedade. (DA SILVA ARAÚJO et al, p.15)

Este fenômeno citado acima se torna evidente da escola de Jaguarão citada neste trabalho.

\title{
5. Conclusões
}


Podemos concluir que a sociabilidade gerada através do processo de inclusão destes indivíduos nas classes regulares, faz com que o material disponibilizado em libras e a convivência se tornam uma unidade caminhando juntas e trazendo um bom modelo a ser seguido.

O referido local se adaptou as necessidades desde tipo de alfabetização, primando pela inclusão destes alunos em classe regular com os demais alunos, proporcionando uma nova forma de ensino destes indivíduos, atualmente recebendo alunos de toda a referida cidade. Estes indivíduos recebem monitoria de um profissional especializado durante as aulas, portanto os educadores trabalham em uma docência compartilhada, aproveitando a troca de conhecimentos que enriquecendo seus trabalhos como educadores que dividem o mesmo espaço, proporcionando para os alunos uma convivência enriquecedora durante suas praticas de alfabetização.

Os materiais usados e os minicursos disponibilizados são de extrema importância e necessidade bem como a presença do monitor, para que essas praticas de ensino e aprendizagem aconteçam e obtenham sucesso, bem como o comprometimento dos profissionais que trabalham no referido local, quanto mais conhecimento esses indivíduos tenham sobre a temática e a linguagem em libras, melhor será a convivência e o aprendizado. Quanto aos estagiários recebem o material disponibilizado na escola, trabalham de em processo de docência compartilhada dividindo espaço em sala de aula com o monitor responsável pelos alunos que necessitam de acompanhamento, diminuindo as dificuldades de adaptação deste profissional no referido local.

Os materiais disponibilizados para os alunos, o acompanhamento do monitor em docência compartilhada, a busca dos demais alunos que frequentam a escola pelo conhecimento da linguagem em libras faz com que as trocas de experiência gere um local onde a inclusão proporciona a integração desses indivíduos, fazendo com que consigam criar laços de amizade sem que a falta de linguagem falada seja um empecilho, formando um modelo a ser seguido.

\section{Referências}

BRABO, Gabriela Maria Barbosa. Políticas de Inclusão Escolar e Formação de Professores: Atendimento Educacional Especializado-AEE Segundo o texto da Política de Educação Possibilidades Pedagógicas na Universidade Federal do Rio Grande do Sul- UFRGS. In Escolarização e deficiência [ recurso eletrônico]: configurações nas politicas de inclusão escolar/ Claudio Roberto Baptista( organizador) - São Carlo: Marquezine \& Manzini: ABPEE, 2015, p. 237-250. Disponível: 

e-ISSN 2016/Atual: 2525-7870 | e-ISSN 2015/2016: 2447-018X

https://www.lume.ufrgs.br/bitstream/handle/10183/116627/000967507.pdf?sequence=1 Acessado em 27 de julho de 2016.

DA SILVA ARAÚJO, Danielle Mirelli; DE ANDRADE SOUSA, Wilma Pastor. A INFLUÊNCIA DA LIBRAS NO PROCESSO EDUCACIONAL DE ESTUDANTES SURDOS EM ESCOLA REGULAR. Disponível: https://www.ufpe.br/ce/images/Graduacao_pedagogia/pdf/2006.2/a\%20influncia\%20da\%20li bras $\% 20$ no $\% 20$ processo $\% 20$ educacional $\% 20 \mathrm{de} \% 20$ estudantes $\% 20$ surdos $\% 20 \mathrm{em} \% 20 \mathrm{escola}$ \%20regular.pdf Acessado em 27 de julho de 2016.

Especial, na Perspectiva Inclusiva SEESP/MEC; 01/2008 Disponível em http://www.pmpf.rs.gov.br/servicos/geral/files/portal/AEE_Apresentacao_Completa_01_03_2 008.pdf Acessado em 27 de julho de 2016.

FOTOS. O autor, CARDOSO, Baiarde. Fotografadas em 05 de outubro de 2016.

GONCALVES, H. B.; FESTA, P. S. V.. Metodologia do professor no ensino de alunos surdos. Ensaios Pedagógicos (Curitiba), v. 6, p.3, 2013.

RECHICO, C. F. \& MAROSTEGA, V. L. (Re) pensando o papel do educador especial no contexto da inclusão de alunos surdos. Revista do Centro de Educação. v. 19, 2002, p. 7-8.

RIJO, M. A Inclusão de Alunos Surdos nas Escolas Públicas de Passo Fundo. Trabalho de conclusão Curso de Especialização: Educação Profissional e Tecnológica Inclusiva. Cuiabá: Instituto Federal do Mato Grosso, 2009, p.20. 